\title{
Crescimento e produtividade da abobrinha italiana: efeito da concentração iônica da solução nutritiva
}

\section{Growth and yield of summer squash: effect of the ionic concentration of nutrient solution}

\author{
André Samuel Strassburger ${ }^{1 *}$; Roberta Marins Nogueira Peil²; Leandro Andrade da \\ Fonseca $^{3}$; Tiago Zanatta Aumonde ${ }^{4}$
}

\begin{abstract}
Resumo
Com o objetivo de avaliar o efeito de diferentes concentrações iônicas da solução nutritiva sobre o crescimento e a produtividade da abobrinha italiana cultivada em substrato de casca de arroz in natura com recirculação dos lixiviados, foram realizados dois experimentos em duas épocas de cultivo: primavera-verão de 2005 e verão-outono de 2006, em Pelotas, RS. Quatro concentrações iônicas da solução nutritiva (com base na condutividade elétrica - CE) foram estudadas: 1,3; 1,7; 2,1 e 4,2 dS $\mathrm{m}^{-1}$. Determinou-se o crescimento da cultura, por meio da quantificação da produção e da partição de massa seca acumulada ao final dos ciclos de cultivo pelos diferentes órgãos aéreos da planta (folha, caule e frutos), e a produtividade. Os resultados obtidos nos experimentos indicam que concentrações iônicas iguais ou inferiores a $1,7 \mathrm{dS} \mathrm{m}^{-1}$ são limitantes para o adequado crescimento e produtividade da cultura. O efeito da alta concentração iônica da solução nutritiva (acima de $2,1 \mathrm{dS} \mathrm{m}^{-1}$ ) sobre a produção e a partição de massa seca varia de acordo com ciclo de cultivo. A menor disponibilidade de radiação solar no período de verão-outono minimiza os efeitos das diferentes concentrações da solução nutritiva sobre a produção e a partição de massa seca para os frutos, bem como sobre a produtividade. Os frutos representaram de 28 a $52 \%$ da massa seca total da parte aérea das plantas. Apenas na solução nutritiva com CE de 2,1 dS m $\mathrm{dS}^{-1}$ e em período de crescente disponibilidade de radiação solar (primavera-verão), os frutos representaram os maiores drenos de fotoassimilados. Segundo os modelos matemáticos, a condutividade elétrica da solução nutritiva que maximizaria a produção de matéria seca e a produtividade é de aproximadamente $3,0 \mathrm{dS} \mathrm{m}^{-1}$, em ambos os ciclos de cultivo.

Palavras-chave: Cucurbita pepo L. Cultivo sem solo. Recirculação dos lixiviados. Substrato de casca de arroz. Produção e partição de massa seca.
\end{abstract}

\begin{abstract}
With the objective of evaluating the effect of different ionic concentrations of the nutrient solution on growth of summer squash cultivated in raw rice husk substrate with leaching recirculation, two experiments were conducted in two crop-seasons: spring-summer of 2005 and summer-autumn of 2006, in Pelotas, RS. Four ionic concentrations of the nutrient solution (based on electrical conductivity - EC) were studied: $1.3 ; 1.7 ; 2.1$ and $4.2 \mathrm{dS} \mathrm{m}^{-1}$. Crop growth was determinated by the accumulated dry mass production and partitioning among the different above-ground plant organs (leafs, stem and fruits) at
\end{abstract}

\footnotetext{
1 Discente do curso de Doutorado em Sistema de Produção Agrícola Familiar. Universidade Federal de Pelotas, Faculdade de Agronomia Eliseu Maciel, Departamento de Fitotecnia, UFPEL. Campus Universitário s/n, Caixa Postal: 354, CEP: 96010-900 Pelotas, RS. E-mail: strassburger.as@gmail.com

2 Professora Associada. E-mail: rmpeil@ufpel.edu.br

3 Discente do curso de Mestrado em Sistema de Produção Agrícola Familiar. E-mail: dafonsecaleandro@yahoo.com.br

4 Discente do Curso de Fisiologia Vegetal. E-mail: tiago.aumonde@gmail.com

* Autor para correspondência
} 
the end of the crop-seasons. Fruit yield was also evaluated. The obtained results indicate that ionic concentrations equal or lower than $1.7 \mathrm{dS} \mathrm{m}^{-1}$ were limiting for proper growth and yield of the crop. The effect of high ionic concentration of the nutrient solution (above $2.1 \mathrm{dS} \mathrm{m}^{-1}$ ) on dry mass production and partitioning varied according to the crop-season. The lower solar radiation availability of the summerautumn crop season minimized the effects of the different concentrations of nutrient solution on dry mass production and partitioning to the fruits, as well as on the yield. The fruits comprised from 28 to $52 \%$ of the total above-ground dry mass production. Fruits represented the largest sink of assimilates of the plant only at $2.1 \mathrm{dS} \mathrm{m}^{-1}$ ionic concentration of the nutrient solution and in crescent solar radiation availability condition (spring-summer). According to the mathematics models, the electrical conductivity that maximizes dry mass production and yield is approximately $3.0 \mathrm{dS} \mathrm{m}^{-1}$ for both crop-seasons.

Key words: Cucurbita pepo L. Soiless cultivation. Leaching recirculation. Raw rice husk substrate. Dry mass production and partitioning.

\section{Introdução}

A concentração iônica do meio radicular condiciona a absorção de água e de nutrientes essenciais para o crescimento das plantas e está diretamente relacionada com as condições climáticas locais e sazonais (STANGHELLINI, 1987). O efeito da salinidade depende da sua interação com as variáveis ambientais, como o déficit de pressão de vapor, a temperatura e a radiação solar, sendo que se esse conjunto de fatores não for ajustado, haverá a redução do crescimento das raízes, o que afetará o crescimento e o desenvolvimento da cultura.

Dessa forma, não existe uma recomendação única de concentração iônica da solução nutritiva que seja ótima a ponto de atender as características próprias dos diferentes substratos e as variações climáticas locais e sazonais que determinam descompasso entre a absorção de água e de nutrientes pelas plantas. A maior eficiência da solução nutritiva se dá pela sua adequação simultânea ao substrato e às diferentes épocas do ano. Em épocas de maior demanda evapotranspirativa da atmosfera (elevada radiação solar, temperatura e déficit de pressão de vapor) a planta absorve mais água, devido à maior transpiração, deste modo, a concentração de iônica da solução nutritiva deve ser mais baixa, para facilitar o fluxo de água para a planta.

Montezano (2007) estudando a concentração iônica da solução nutritiva na cultura do meloeiro (nas concentrações de 0,$9 ; 1,3$ e 1,8
$\mathrm{dS} \mathrm{m}^{-1}$ ) observou que, na primavera-verão há um aumento da produção de massa fresca e seca dos frutos com o aumento da concentração de nutrientes. No cultivo de verão-outono, as plantas não respondem a um aumento da concentração de nutrientes da solução nutritiva.

Duarte, Peil e Montezano (2008) também estudaram o efeito da concentração iônica da solução nutritiva na cultura do meloeiro, todavia em concentrações mais elevadas $(1,9 ; 2,3$ e 2,9 $\mathrm{dS} \mathrm{m}^{-1}$ ) e verificaram que, nesse intervalo, a produção de massa seca e a produtividade não são influenciados pela concentração iônica da solução nutritiva e recomendam a concentração de $1,9 \mathrm{dS} \mathrm{m}^{-1}$ por representar uma economia de fertilizantes sem prejuízos a produção.

O crescimento das plantas pode ser definido como a produção e a partição da biomassa (massa seca e fresca) entre os diferentes órgãos da planta (MARCELIS, 1993), sendo diretamente influenciado pela quantidade e pela proporção dos nutrientes fornecidos pela solução nutritiva (CORTÉS, 1999). As mudanças na absorção de água e de nutrientes proporcionadas pela variação da concentração iônica no sistema radicular levam a alterações da fisiologia das plantas. Estas relacionam-se, dentre outros fatores, à abertura estomática e ao aumento ou diminuição da área foliar, estando esses fatores ligados à eficiência fotossintética, e consequentemente, à produção de massa seca pelas plantas.

O processo de industrialização do arroz gera 
uma grande fração de casca. A utilização desse resíduo como substrato no cultivo sem solo é uma alternativa importante que reduz seu acúmulo no meio ambiente, propicia uma destinação a esse subproduto agrícola poluente e, ainda, pode reduzir os custos de produção devido a seu baixo custo. Vários trabalhos já foram realizados com o meloeiro utilizando a casca de arroz in natura com substrato em sistema fechado (BACCHI, 2004; MONTEZANO, 2007; DUARTE; PEIL; MONTEZANO, 2008; DUARTE et al., 2008) sem a necessidade de descarte e reposição completa da solução nutritiva, não ocorrendo prejuízos para a produção de massa seca, o que reduz a quantidade de solução nutritiva descartada no meio ambiente e, consequentemente, o impacto ambiental causado pelo sistema.

Trabalhos sobre formulações nutritivas têm sido realizados para o tomateiro (ANDRIOLO; ROSS; WITTER, 2004; FREIRE et al., 2010), para o pepineiro (ESPÍNOLA; ANDRIOLO; BARTZ, 2001), para o meloeiro (BACCHI, 2004; ANDRIOLO et al., 2005a; MONTEZANO, 2007; DUARTE; PEIL; MONTEZANO, 2008; DUARTE et al., 2008) e para a alface (FILGUEIRAS; TAKAHASHI; BENINNI, 2002; MONTEZANO, 2003; ANDRIOLO et al., 2005b), mas são escassas as informações sobre a composição e a concentração da solução nutritiva para a cultura da abobrinha italiana e, em substrato de casca de arroz in natura, são inexistentes.

Portanto, este trabalho teve como objetivo quantificar a produção e a partição de massa seca entre os órgãos aéreos, bem como a produtividade da abobrinha italiana cultivada em substrato de casca de arroz in natura com recirculação dos lixiviados em dois diferentes ciclos de cultivo, observando a influência da concentração de nutrientes da solução nutritiva.

\section{Material e Métodos}

Os experimentos foram realizados em uma estufa de cultivo modelo "Arco Pampeana", disposta no sentido Norte-Sul, revestida com filme de polietileno de baixa densidade (150 $\mu \mathrm{m}$ de espessura), compreendendo uma área de $210 \mathrm{~m}^{2}(10 \times 21 \mathrm{~m})$, com o solo coberto com plástico dupla face branco-preto, localizada no Campus da Universidade Federal de Pelotas (com coordenadas geográficas aproximadas de: latitude $31^{\circ} 52^{\prime} \mathrm{S}$, longitude $52^{\circ} 21^{\prime} \mathrm{W}$ e altitude de $13 \mathrm{~m}$ ).

O primeiro experimento foi realizado na primavera-verão do ano de 2005. A semeadura da abobrinha italiana (Cucurbita pepo var. melopepo cv. Caserta) foi realizada em 03/10/2005 e, 18 dias após, seu transplante. O segundo experimento foi realizado no período de verão-outono de 2006. A semeadura foi realizada no dia 24/02/2006 e o transplante 19 dias após.

Em ambos experimentos as mudas foram produzidas em bandejas de poliestireno expandido com 72 células, contendo como substrato vermiculita, em sistema de bandejas flutuantes para a irrigação de mudas. A solução nutritiva utilizada nessa fase foi a recomendada por Castro (1999), na concentração de 50\% para os macronutrientes e de $100 \%$ para os micronutrientes, correspondendo à condutividade elétrica (CE) de $1,1 \mathrm{dS} \mathrm{m}^{-1}$.

As mudas foram transplantadas (com aproximadamente três a quatro folhas verdadeiras) individualmente para sacos plásticos contendo 13 litros de casca de arroz in natura, perfurados na base para drenagem da solução nutritiva excedente à capacidade máxima de retenção de água do substrato. Os sacos foram dispostos em 12 fileiras duplas de canais de madeira $(7,5 \times 0,35 \times 0,20 \mathrm{~m})$, com declividade de $2 \%$, distância interna de $0,50 \mathrm{~m}$, passeio de 1,20 m e espaçamento de $0,70 \mathrm{~m}$ entre sacos, proporcionando uma densidade de 1,68 
plantas $\mathrm{m}^{-2}$ (Figura 1). Os canais foram revestidos internamente com filme de polietileno dupla face, de maneira a formar canais impermeáveis, que se fechavam sobre os sacos. Um tanque de armazenamento da solução nutritiva $(500$ L) foi enterrado próximo à extremidade de cota menor ao final de cada linha dupla de canais. Um conjunto moto-bomba ( $1 / 4 \mathrm{HP})$ em cada tanque impulsionava a solução nutritiva para a cota de maior valor do canal através de um cano de PVC de $25 \mathrm{~mm}$. A partir deste ponto, a solução era fornecida às plantas através de uma mangueira de polietileno de $1 / 2$ polegada perfurada para a colocação de dois espaguetes por saco. As plantas foram fertirrigadas por um fluxo intermitente, programado por um temporizador em 8 intervalos de tempo pré-estabelecidos, com base em dados de consumo d'água da cultura da abobrinha cultivada a campo (KLOSOWSKI; LUNARDI; SANDANIELO, 1999), devido à falta de dados referentes à cultura em ambiente protegido, mais $20 \%$ de solução nutritiva para drenagem, resultando em 0,80 e $0,80 \mathrm{~L}$ planta $\mathrm{dia}^{-1}$ na fase inicial (crescimento vegetativo) e 3,2 e 1,60 L planta dia $^{-1}$ na segunda fase (florescimento e frutificação) nos experimentos de primaveraverão e de verão-outono, respectivamente. A solução lixiviada era coletada e conduzida de volta ao tanque de armazenamento através dos canais de polietileno, constituindo-se, assim em um sistema fechado de cultivo.

As plantas foram tutoradas individualmente, com um fio de ráfia preso ao colo da planta e estendido até uma linha de arame presa à estrutura da estufa na altura de $3,50 \mathrm{~m}$.
O fator experimental estudado foi a concentração iônica da solução nutritiva em quatro níveis pré-estabelecidos, com base na solução padrão recomendada por Castro (1999) para a cultura da abobrinha italiana em substrato de lã-de-rocha, cujas concentrações de macronutrientes (em mmol L-1) são: 16,0 de $\mathrm{NO}_{3}^{-}$ ; 1,5 de $\mathrm{H}_{2} \mathrm{PO}_{4}^{-} ; 2,7$ de $\mathrm{SO}_{4}^{-2} ; 1,0$ de $\mathrm{NH}_{4}^{+} ; 7,5 \mathrm{de}$ $\mathrm{K}^{+} ; 5,0$ de $\mathrm{Ca}^{2+}$ e 2,2 de $\mathrm{Mg}^{2+}$. A condutividade elétrica obtida foi de $2,1 \mathrm{dS} \mathrm{m}^{-1}$. Os níveis do fator foram constituídos por concentrações múltiplas dos macronutrientes da solução nutritiva padrão $(0,6 ; 0,8 ; 1,0$ e 2,0$)$, de maneira a serem obtidos valores de $\mathrm{CE}$ de 1,$3 ; 1,7 ; 2,1$ e $4,2 \mathrm{dS} \mathrm{m}^{-1}$. Os micronutrientes foram mantidos na concentração original nas quatro soluções (em mg L $\left.\mathrm{L}^{-1}\right): 4,00$ de Fe; 0,56 de Mn; 0,26 de Zn; 0,03 de Cu; 0,05 de Mo e 0,22 de B. Para o preparo das soluções, utilizou-se água da chuva $\left(\mathrm{CE}=0,0 \mathrm{dS} \mathrm{m}^{-1}\right.$ e $\mathrm{pH}$ $=7,0)$.

As soluções nutritivas foram monitoradas diariamente por meio das medidas de CE (empregando-se um eletrocondutivímetro manual digital) e de $\mathrm{pH}$ (empregando-se um pHmetro manual digital), sendo este mantido numa faixa de $6,0 \pm 0,5$ pela adição de solução de correção à base de hidróxido de potássio $(\mathrm{KOH}$ $1 \mathrm{~N})$ ou ácido sulfúrico $\left(\mathrm{H}_{2} \mathrm{SO}_{4} 1 \mathrm{~N}\right)$. As correções da concentração iônica das soluções nutritivas foram realizadas mediante a adição de água ou solução estoque concentrada quando o valor da condutividade elétrica apresentava uma variação da ordem de $10 \%$ acima ou abaixo do valor préestabelecido, respectivamente. 


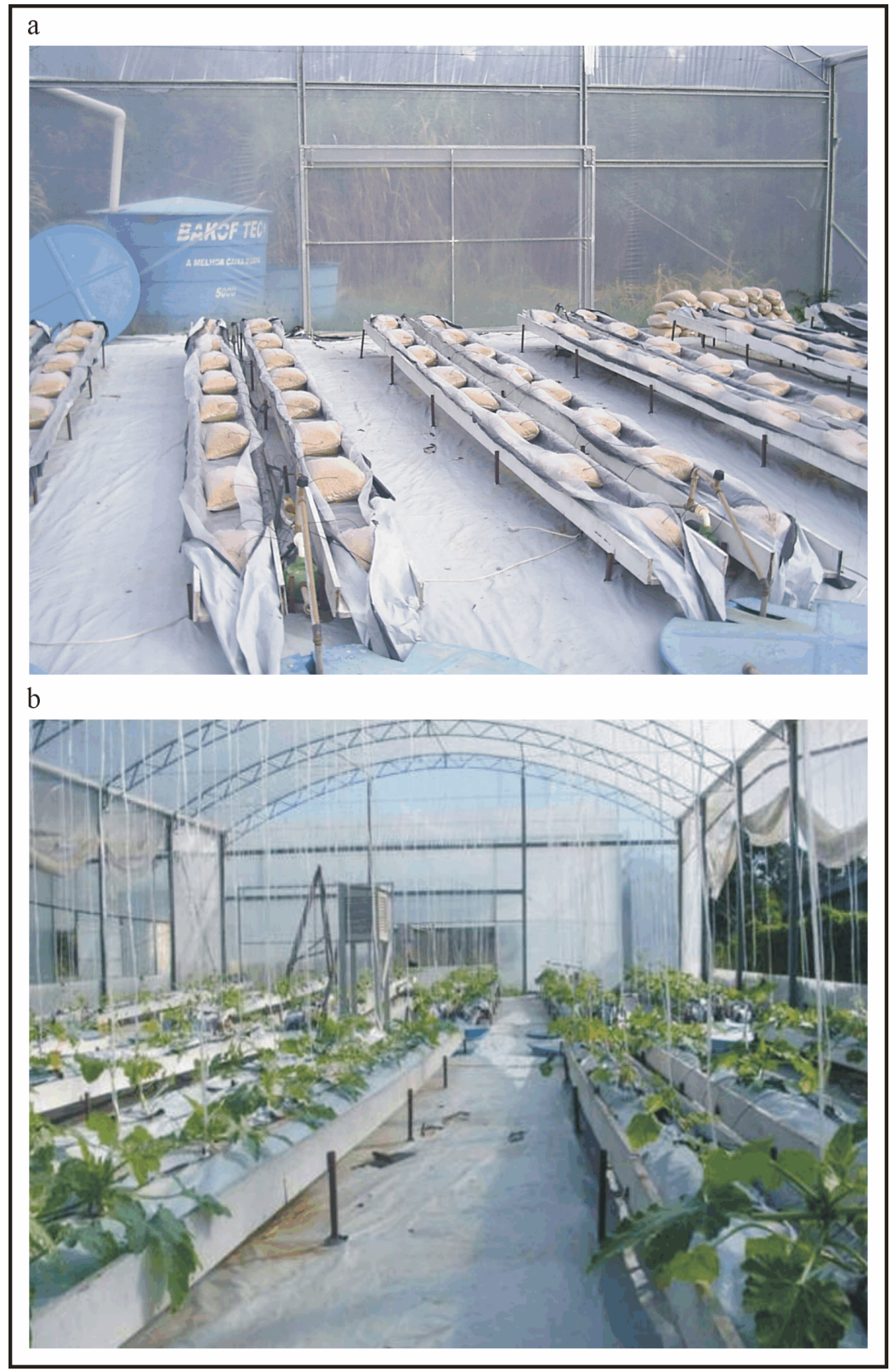

Figura 1. Sistema de cultivo sem solo com recirculação da solução nutritiva e substrato de casca de arroz in natura utilizado na pesquisa. a) Sistema pronto para o transplante das mudas; b) Sistema em pleno funcionamento. Pelotas, UFPEL, 2006.

Após o transplante das mudas, selecionou-se duas plantas por repetição, sobre as quais mantevese total controle da colheita e remoção de folhas. O crescimento da cultura foi determinado pela quantificação da produção e da partição de massa seca aérea das plantas controle aos 68 e 55 dias após o transplante, no experimento de primavera-verão e de verão-outono, respectivamente, incluindo os frutos colhidos durante o processo produtivo e as folhas provenientes da desfolha antecipada. As plantas foram separadas em três frações: folhas (incluindo pecíolos), caule e frutos. A massa seca total da parte aérea da planta correspondeu à soma das folhas, caules e frutos, e a massa seca vegetativa à soma das folhas e caules. Estas frações foram pesadas para a obtenção da massa fresca e 
secas em estufa de ventilação forçada a $65^{\circ} \mathrm{C}$ até massa constante, para a obtenção da massa seca. A produtividade foi obtida pela pesagem dos frutos após a colheita. A radiação solar global incidente no exterior foi obtida na estação Agroclimatológica de Pelotas, localizada a aproximadamente $600 \mathrm{~m}$ do local dos experimentos. Os dados referentes à temperatura e umidade relativa foram coletados em um termohigrógrafo, instalado a 1,5 m de altura, no centro da estufa de cultivo.

O delineamento experimental adotado foi completamente casualizado, com três repetições de cada nível do fator experimental. Cada parcela experimental foi composta por um conjunto de linhas duplas de canais de cultivo (com 22 plantas no total), tanque de armazenamento de solução nutritiva e moto bomba. Os resultados foram submetidos à decomposição em componentes polinomiais e as médias referentes à partição de massa seca, comparadas pelo teste DMS de Fisher com um nível de 5\% de probabilidade de erro.

\section{Resultados e Discussão}

As diferentes concentrações iônicas, expressas pela condutividade elétrica (CE) das soluções nutritivas avaliadas, influenciaram a produção (Figura 2) e a partição (Tabela 1) de massa seca dos diferentes órgãos aéreos das plantas, bem como a produtividade (Figura 3) em ambos experimentos.

Tabela 1. Partição de massa seca entre os órgãos vegetativos aéreos em plantas da abobrinha italiana cultivada em casca de arroz in natura com solução nutritiva recirculante em função da concentração iônica da solução nutritiva nos ciclos de primavera-verão e verão-outono. Pelotas, UFPEL, 2006.

\begin{tabular}{|c|c|c|c|c|}
\hline \multirow{2}{*}{ 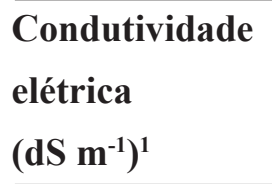 } & \multicolumn{4}{|c|}{ Relação de massa seca $\left(\mathrm{g} \mathrm{g}^{-1}\right)$} \\
\hline & Fruto / Planta & Vegetativo $^{2}$ / Planta & Caule/Vegetativo & Folha/Vegetativo \\
\hline \multicolumn{5}{|c|}{ Primavera - Verão $^{3}$} \\
\hline 1,3 & $0,38 \quad c^{5}$ & $0,62 \mathrm{~b}$ & $0,22 \mathrm{a}$ & $0,78 \mathrm{a}$ \\
\hline 1,7 & $0,32 \mathrm{~d}$ & $0,68 \mathrm{a}$ & $0,21 \mathrm{a}$ & $0,79 \mathrm{a}$ \\
\hline 2,1 & $0,52 \mathrm{a}$ & $0,48 \quad \mathrm{~d}$ & $0,23 \mathrm{a}$ & $0,77 \mathrm{a}$ \\
\hline 4,2 & $0,45 \mathrm{~b}$ & $0,55 \mathrm{c}$ & $0,24 \mathrm{a}$ & $0,76 \mathrm{a}$ \\
\hline $\mathrm{CV}$ & 8,01 & 5,76 & 18,83 & 5,48 \\
\hline \multicolumn{5}{|l|}{ Verão - Outono ${ }^{4}$} \\
\hline 1,3 & $0,45 \mathrm{a}$ & $0,55 \mathrm{~b}$ & $0,18 \mathrm{a}$ & $0,82 \mathrm{c}$ \\
\hline 1,7 & $0,30 \mathrm{~b}$ & $0,70 \mathrm{a}$ & $0,14 \mathrm{~b}$ & $0,86 \mathrm{~b}$ \\
\hline 2,1 & $0,39 \mathrm{a}$ & $0,61 \mathrm{~b}$ & $0,13 \mathrm{~b}$ & $0,87 \mathrm{~b}$ \\
\hline 4,2 & $0,28 \mathrm{~b}$ & $0,72 \mathrm{a}$ & $0,08 \mathrm{c}$ & $0,92 \mathrm{a}$ \\
\hline $\mathrm{CV}$ & 18,15 & 9,97 & 22,77 & 3,48 \\
\hline
\end{tabular}

1. Concentração iônica expressa pela condutividade elétrica da solução nutritiva; ${ }^{2}$. Massa seca da fração vegetativa (Vegetativo) corresponde à soma: folhas + caule + pecíolos; ${ }^{3}$ Experimento realizado durante o período de primaveraverão; ${ }^{4}$. Experimento realizado durante o período de verão-outono; ${ }^{5 .}$ Médias seguidas pelas mesmas letras nas colunas, em cada ciclo de cultivo, não diferem entre si pelo teste DMS de Fisher em nível de 5\% de probabilidade de erro. 


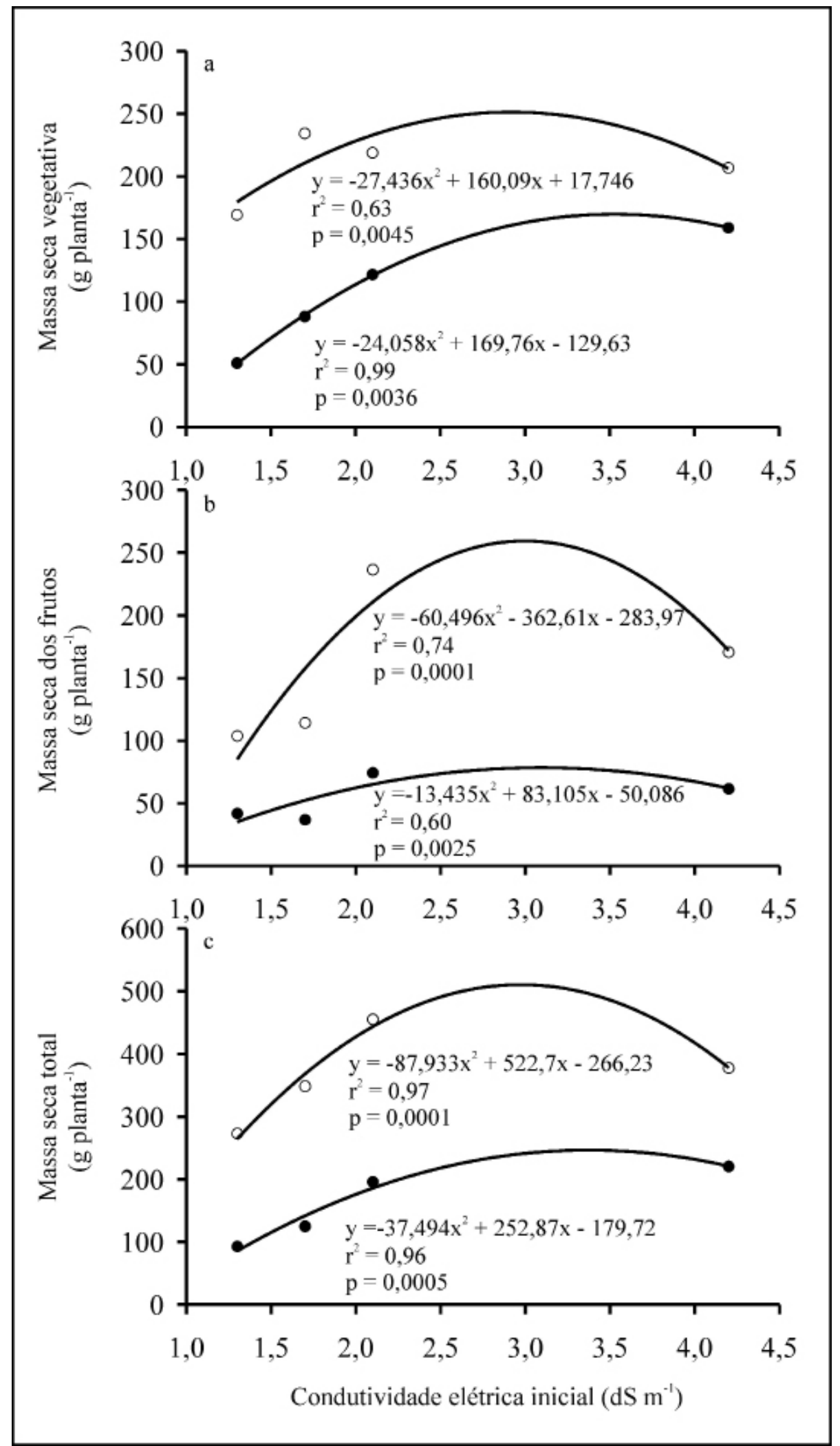

Figura 2. Produção de massa seca da fração vegetativa (a), dos frutos (b) e do total da parte aérea (c) da abobrinha italiana em função da concentração iônica da solução nutritiva no ciclo de primavera-verão (o) e de verão-outono (•). Pelotas, UFPEL, 2006. 


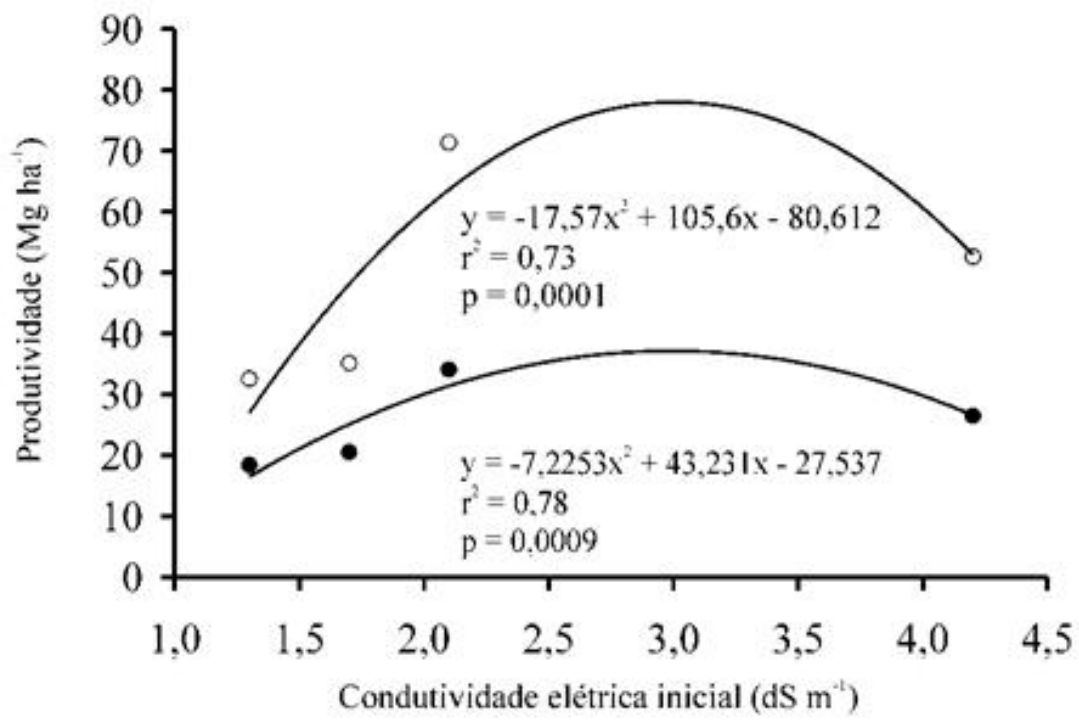

Figura 3. Produtividade da abobrinha italiana em função da concentração de nutrientes da solução nutritiva no ciclo de primavera-verão (०) e de verão-outono (•). Pelotas, UFPEL, 2006.

No experimento de primavera-verão, a massa seca da fração vegetativa (Figura 2a) apresentou uma redução média de 22,6 e 5,5\% nos tratamentos com CE de 1,3 e 4,2 $\mathrm{dS} \mathrm{m}^{-1}$, respectivamente, quando comparados à concentração de referência $(\mathrm{CE}$ de $\left.2,1 \mathrm{dS} \mathrm{m}^{-1}\right)$. O tratamento com $\mathrm{CE}$ de $1,7 \mathrm{dS} \mathrm{m}^{-1}$ apresentou valor médio $7,1 \%$ superior ao tratamento de referência, que apresentou uma produção média de massa seca vegetativa de $218,8 \mathrm{~g}_{\text {planta }}{ }^{-1}$. A massa seca dos frutos (Figura 2b) sofreu maior influência pela variação da concentração iônica da solução nutritiva do que a massa seca vegetativa. Houve uma redução da ordem de 56,1; 51,7 e 27,8\%, respectivamente para os tratamentos com $\mathrm{CE}$ de 1,3; 1,7 e $4,2 \mathrm{dS} \mathrm{m}^{-1}$, quando comparados ao tratamento com $\mathrm{CE}$ de 2,1 dS m $\mathrm{dS}^{-1}$, que apresentou uma produção média de massa seca de frutos de 236,5 $\mathrm{g}_{\text {planta }}{ }^{-1}$. Estes resultados levaram à queda nos valores de massa seca total produzida pela parte aérea das plantas (Figura 2c) da ordem de 40,0; 23,4 e 17,1\% para os tratamentos com CE de 1,3; 1,7 e 4,2 dS m-1, respectivamente, em comparação ao tratamento de referência, que apresentou uma produção média de massa seca total de 455,3 g planta $^{-1}$. Os resultados obtidos se ajustaram a uma curva polinomial quadrática com ponto de máxima em 2,9; 3,0 e 3,0 $\mathrm{dS} \mathrm{m}^{-1}$, respectivamente, para a massa seca da fração vegetativa, dos frutos e do total da planta.

No experimento de verão-outono, a massa seca da fração vegetativa foi reduzida em 58,1 e $27,6 \%$ nos tratamentos com CE de 1,3 e 1,7 $\mathrm{dS} \mathrm{m}^{-1}$, respectivamente, quando comparado ao tratamento

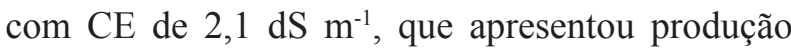
média de 121,6 g planta $^{-1}$. O tratamento com CE de $4,2 \mathrm{dS} \mathrm{m}^{-1}$ apresentou um acréscimo de $23,5 \%$ para esta variável. A produção de massa seca dos frutos foi reduzida em todos os tratamentos, na ordem de 43,7; 50,4 e 17,6\%, para os tratamentos com CE de 1,3; 1,7 e 4,2 $\mathrm{dS} \mathrm{m}^{-1}$, respectivamente, quando comparados ao tratamento de referência, cuja produção média foi de 74,4 g planta $^{-1}$. Assim, os resultados para a produção de massa seca total, apresentaram redução de 52,6 e $36,2 \%$ para os tratamentos com CE de 1,3 e $1,7 \mathrm{dS} \mathrm{m}^{-1}$, respectivamente, e um acréscimo de $11,1 \%$ no tratamento com $\mathrm{CE}$ de $4,2 \mathrm{dS} \mathrm{m}^{-1}$ quando comparado ao tratamento de referência, cuja produção média de massa seca total foi de $196,0 \mathrm{~g}$ planta $^{-1}$. Os resultados obtidos se ajustaram a uma curva polinomial quadrática com ponto de máxima em 3,$5 ; 3,1$ e $3,4 \mathrm{dS} \mathrm{m}^{-1}$, respectivamente, para a massa seca da fração vegetativa, dos frutos e do total da planta.
A produtividade (Figura 3) apresentou 
comportamento semelhante ao da massa seca dos frutos (Figura 2b). Os tratamentos 1,3; 1,7 e 4,2 $\mathrm{dS} \mathrm{m}^{-1}$, no ciclo de primavera-verão, apresentaram uma redução de 54,4; 50,8 e 26,3\% em relação ao tratamento $2,1 \mathrm{dS} \mathrm{m^{-1 }}$, que apresentou uma produtividade de $71,4 \mathrm{Mg} \mathrm{ha}^{-1}$. No ciclo de verãooutono, as diferenças de produtividade entre os tratamentos foram menos marcantes, assim como a produção de massa seca. A redução de produtividade foi de 46,0; 39,8 e 22,4\% para os mesmos tratamentos, respectivamente, em comparação ao tratamento de referência no qual se obteve uma produtividade de $34,1 \mathrm{Mg} \mathrm{ha}^{-1}$. Assim, os resultados se ajustaram a uma curva polinomial quadrática com ponto de máxima em $3,0 \mathrm{dS} \mathrm{m}^{-1} \mathrm{em}$ ambos experimentos.

No ciclo de primavera-verão, ao se analisar a produção de massa seca da fração vegetativa e dos frutos (Figura 2a e b) e a partição de massa seca para os frutos e para a fração vegetativa (Tabela 1) observa-se que as plantas do tratamento com CE de $1,7 \mathrm{dS} \mathrm{m}^{-1}$, apresentaram um crescimento vegetativo satisfatório. No entanto, o mesmo não ocorreu em relação aos frutos. Durante ambos os experimentos, observou-se que as plantas dos tratamentos com condutividade elétrica 1,3 e 1,7 $\mathrm{dS} \mathrm{m}^{-1}$ apresentaram sintomas de deficiências nutricionais, principalmente de nitrogênio e cálcio, sendo estes mais acentuados na CE mais baixa, a qual limitou a produção de massa seca vegetativa e dos frutos. Nos dois experimentos, os resultados obtidos com o tratamento com CE de $1,3 \mathrm{dS} \mathrm{m}^{-1}$ podem ser atribuídos à baixa disponibilidade de nutrientes na solução nutritiva, o que limitou o crescimento da cultura. No tratamento com CE de $1,7 \mathrm{dS} \mathrm{m}^{-1}$, possivelmente, as quantidades dos nutrientes presentes na solução nutritiva estavam próximas dos limites mínimos exigidos pela cultura, determinando um crescimento vegetativo satisfatório no ciclo de primavera-verão. Entretanto, os níveis de nutrientes dessa solução nutritiva não foram suficientes para manter o perfeito crescimento dos frutos em ambos experimentos, ocasionando a podridão apical (deficiência de $\mathrm{Ca}$ ) em grande parte dos mesmos, provocando o aborto ou a colheita antecipada, reduzindo o número de frutos por planta e a alocação de massa seca para os frutos (Figura $2 b$ e Tabela 1). Segundo vários autores (MARCELIS, 1996; HEUVELINK, 1997; PEIL; GÁLVEZ, 2002, 2005), para as hortaliças de fruto, um menor número de frutos induz a um menor acúmulo de massa seca nesse compartimento, devido a uma limitação do número de drenos da planta, o que foi determinante para o resultado obtido no tratamento com $\mathrm{CE}$ de $1,7 \mathrm{dS} \mathrm{m}^{-1}$ no ciclo de primavera-verão. No ciclo de verão-outono, as duas menores concentrações de nutrientes foram limitantes para o crescimento da cultura (Figura 2).

O tratamento com a maior concentração iônica da solução nutritiva $\left(4,2 \mathrm{dS} \mathrm{m}^{-1}\right)$ pouco alterou os valores de produção de massa seca em comparação ao tratamento de referência, tendendo a reduzi-los, com exceção da massa seca da fração vegetativa e da massa seca total no experimento de verãooutono, as quais foram ligeiramente superiores às da CE de 2,1 dS m (Figura 2a e b). A concentração iônica do meio radicular, além de condicionar a absorção de nutrientes essenciais, influencia, também, a absorção de água para o crescimento das plantas. Soluções nutritivas mal formuladas, com uma concentração iônica muito elevada, provocam, em um primeiro momento, a inibição da absorção de água, induzindo a planta a um estresse hídrico, e em um momento posterior, a própria absorção mineral é inibida (LI, 2000). Entretanto, a resposta à alta concentração iônica no presente trabalho variou de acordo com as condições evapotranspirativas da época de cultivo confirmando as indicações de Stanghellini (1987) e Li (2000).

Durante o experimento de primavera-verão, o tratamento com CE de 4,2 $\mathrm{dS} \mathrm{m}^{-1}$ possivelmente interferiu no processo de absorção de água, sendo observada a 'murcha' antecipada das plantas durante o nictêmero em comparação aos demais tratamentos. A alta demanda evapotranspirativa da atmosfera do período associada à alta concentração 
iônica da solução nutritiva ocasiona um potencial hídrico reduzido no meio radicular, levando a que o fluxo de água seja prejudicado, culminando em uma menor produção de massa seca dos frutos (Figura 2b), e por consequência, uma menor produção de massa seca total, quando comparado ao tratamento de referência. As plantas respondem à salinidade com o ajustamento osmótico, entretanto a produção é reduzida. Adicionalmente ao estresse hídrico, a condutância estomática é afetada, tendo como resultado o decréscimo na fotossíntese (LI, 2000).

No experimento de verão-outono, não ocorreu essa diferença na 'murcha' entre as plantas do tratamento com concentração iônica mais elevada e as demais, explicando a maior produção de massa seca na fração vegetativa e a maior produção de massa seca total neste tratamento. Tem sido demonstrado que modificações nas variáveis ambientais refletemse rapidamente no fluxo transpiratório das culturas (KITTAS; KATSOULAS; BAILLE, 2001), cuja rapidez de resposta é notável em cultivos em substrato. Neste sistema de cultivo, quando o fluxo transpiratório aumenta, o teor de água no interior do substrato diminui rapidamente, elevando a salinidade (ANDRIOLO et al., 2005a). No ciclo de verão-outono, ocorreu a redução da temperatura média e o aumento da umidade relativa média em comparação ao experimento de primavera-verão. No ciclo de primavera-verão, a temperatura média das máximas foi de $32,0^{\circ} \mathrm{C}$ (variando de 22 a $44^{\circ} \mathrm{C}$ ) e a média das mínimas em torno de $16,5^{\circ} \mathrm{C}$ (variando de 10 a $25^{\circ} \mathrm{C}$ ). Durante o período de verão-outono, a temperatura média das máximas foi de $28,4^{\circ} \mathrm{C}$ (variando de 20 a $42^{\circ} \mathrm{C}$ ) e a média das mínimas foi de $15,3^{\circ} \mathrm{C}$ (variando de 7 a $20^{\circ} \mathrm{C}$ ). Em ambos experimentos, a umidade relativa média das máximas ficou em 98\%, devido ao fechamento da estufa ao entardecer, entretanto, a média das mínimas foi de 45,6\% (variando de 30 a $80 \%$ ) no experimento de primavera-verão e de $60,3 \%$ (variando de 44 a $80 \%$ ) no experimento de verãooutono, o que caracteriza uma maior demanda evapotranspirativa da atmosfera no primeiro ciclo de cultivo.

No experimento de primavera-verão, nas duas maiores concentrações iônica a alocação proporcional de massa seca para os frutos foi mais elevada em comparação aos demais tratamentos (Tabela 1). Entretanto, apenas no tratamento com CE de 2,1 dS m m $^{-1}$ a maior fração da massa seca produzida foi destinada a esta fração. $\mathrm{O}$ incremento da concentração de nutrientes no meio radicular, além da concentração de referência, reduziu a produção de massa seca dos frutos (Figura 2b) e, como a massa seca vegetativa foi semelhante ao tratamento de referência, alterou as relações citadas. Neste ciclo de cultivo, as relações do caule e da folha com a fração vegetativa (Tabela 1) apresentaram valores semelhantes em todos os tratamentos.

No experimento de verão-outono, as plantas dos tratamentos com $\mathrm{CE}$ de 1,3 e $2,1 \mathrm{dS} \mathrm{m}^{-1}$ alocaram maior proporção da massa seca para os frutos em comparação aos outros dois tratamentos (Tabela 1). No entanto, no tratamento com CE de $1,3 \mathrm{dS} \mathrm{m}^{-1}$, o crescimento vegetativo das plantas foi drasticamente reduzido, o que é evidenciado pela menor produção absoluta de massa seca vegetativa (Figura 2a). Como consequência, os frutos, proporcionalmente, contribuíram mais para a constituição da parte aérea da planta, o que, no entanto, não significou uma maior produção absoluta de massa seca desse compartimento (Figura 2b). A menor contribuição proporcional dos frutos para a composição do total da planta no tratamento 1,7 dS m $\mathrm{m}^{-1}$, em ambos os experimentos, pode ser atribuída a menor concentração de nutrientes, que não permitiu o adequado crescimento dos frutos, reduzindo a contribuição proporcional dessa fração para a composição do total da planta. Para o tratamento com CE de 4,2 $\mathrm{dS} \mathrm{m}^{-1}$, a baixa contribuição proporcional dos frutos no ciclo de verão-outono pode ser associada às doses excessivas de nitrogênio na solução nutritiva que favorecem o crescimento vegetativo das culturas, retardando o início da frutificação e reduzem a fixação de frutos (ANDRIOLO; ROSS; WITTER, 2004), 
promovendo o crescimento vegetativo excessivo em detrimento do reprodutivo. A redução do efeito negativo da alta concentração de sais nutrientes sobre o crescimento vegetativo das plantas foi atenuada neste ciclo em que a demanda evapotranpirativa da atmosfera foi menor, justificando as diferenças de resposta para esse tratamento entre os dois ciclos de cultivo.

No ciclo de verão-outono, o aumento da concentração iônica ocasionou maior acúmulo proporcional de massa seca nas folhas dentro do compartimento vegetativo, principalmente no tratamento com CE de 4,2 $\mathrm{dS} \mathrm{m}^{-1}$, no qual as folhas representaram aproximadamente $92 \%$ da massa seca da fração vegetativa (Tabela 1), valor acima do observado no experimento de primavera-verão e do relatados na bibliografia para a cultura do pepineiro (59-62\%; PEIL; GÁLVEZ, 2002) e para a cultura do meloeiro (66-72\%; DUARTE et al., 2008).

Observa-se que, as maiores produtividades (Figura3) foram obtidas nas plantas queapresentaram maior capacidade de produção de massa seca dos frutos. O rendimento de um cultivo é determinado pela capacidade das plantas em acumular biomassa (massa seca e fresca) nos órgãos que se destinam a colheita, sendo que um incremento da biomassa destinada a estes órgãos garante um incremento do rendimento (CHALLA; HEUVELINK, 1993). Assim, no experimento de primavera-verão, as plantas do tratamento com $\mathrm{CE}$ de $2,1 \mathrm{dS} \mathrm{m}^{-1}$ apresentaram uma maior produção (Figura 2b) e contribuição proporcional de massa seca dos frutos (Tabela 1), o que elevou a produtividade em comparação aos demais tratamentos. No entanto, no ciclo de verão-outono, a diferença entre os tratamentos em relação à produção de massa seca das frutas foi atenuada, o que, consequentemente, reduziu a diferença de produtividade entre os tratamentos.

No ciclo de primavera-verão ocorreu maior produção de massa seca dos órgãos aéreos das plantas (Figura 2) e maior produtividade (Figura
3) em comparação com o ciclo de verão-outono. A principal causa desses resultados pode ser atribuída à maior radiação solar incidente durante o período que foi de $1445 \mathrm{MJ} \mathrm{m}^{-2}$ (média de 21,25 $\mathrm{MJ} \mathrm{m}^{-2} \mathrm{dia}^{-1}$ ) enquanto que no período de verão-outono foi de 684 $\mathrm{MJ} \mathrm{m}^{-2}$ (média de 12,44 $\mathrm{MJ} \mathrm{m}^{-2}$ dia $^{-1}$ ). Considera-se que em plantas sadias e adequadamente supridas de água e nutrientes, a fotossíntese líquida e a produção de biomassa são proporcionais à quantidade de radiação fotossinteticamente ativa absorvida pelo dossel (MONTEITH, 1972), o que influenciou diretamente a diferença dos resultados obtidos nos dois ciclos de cultivo.

\section{Conclusões}

Concentrações iônicas iguais ou inferiores a 1,7 $\mathrm{dS} \mathrm{m}^{-1}$ são limitantes para o adequado crescimento e produtividade da cultura. $\mathrm{O}$ efeito da alta concentração iônica da solução nutritiva (acima de $2,1 \mathrm{dS} \mathrm{m}^{-1}$ ) sobre a produção e a partição de massa seca varia de acordo com ciclo de cultivo. A menor disponibilidade de radiação solar no período de verão-outono minimiza os efeitos das diferentes concentrações da solução nutritiva sobre a produção e partição de massa seca dos frutos, bem como sobre a produtividade. Os frutos representam de 28 a $52 \%$ da massa seca total da parte aérea das plantas. Apenas na solução nutritiva com CE de 2,1 $\mathrm{dS} \mathrm{m}^{-1}$ e em período de crescente disponibilidade de radiação solar, os frutos representam os maiores drenos de fotoassimilados das plantas. Segundo os modelos matemáticos ajustados, a condutividade elétrica da solução nutritiva que maximizaria a produção e partição de massa seca dos frutos e a produtividade é de aproximadamente $3,0 \mathrm{dS} \mathrm{m}^{-1}$, em ambos os ciclos de cultivo.

\section{Referências}

ANDRIOLO, J. L.; ROSS, T. D.; WITTER, M. Crescimento, desenvolvimento e produtividade do tomateiro cultivado em substrato com três concentrações de nitrogênio na solução nutritiva. Ciência Rural, Santa 
Maria, v. 34, n. 5, p. 1451-1457, 2004.

ANDRIOLO, J. L.; LUZ, G. L.; BORTOLOTTO, O. C.; GODOI, R. S. Produtividade e qualidade de frutos de meloeiro cultivado em substrato com três doses de solução nutritiva. Ciência Rural, Santa Maria, v. 35, n. 4, p. 781-787, 2005a.

ANDRIOLO, J. L.; LUZ, G. L.; WITTER, M. H.; GODOI, R. S.; BARROS, G. T.; BORTOLOTTO, O. C. Growth and yield of lettuce plants under salinity. Horticultura Brasileira, Brasília, v. 23, n. 4, p. 931-934, 2005 b.

BACCHI, S. Crescimento, eficiência no uso da água e dos nutrientes e relação de contaminação do meloeiro cultivado em substratos de casca de arroz. 2004. Dissertação (Mestrado em Agronomia Produção Vegetal) - Faculdade de Agronomia Eliseu Maciel. Universidade Federal de Pelotas, Pelotas.

CASTRO, A. C. Formulación de la solución nutritiva: parámetros de ajuste. In: MILAGROS, M. F.; GÓMEZ, I. M. C. (Ed.). Cultivos sin suelo II. 2. ed. Almería: DGIFAFIAPA, Caja Rural de Almería, 1999. p. 257-266.

CHALLA, H.; HEUVELINK, E. Economic evaluation of crop photosynthesis. Acta Horticulture, Saumane, v. 328, p. 219-228, 1993.

CORTÉS, E. M. Características del riego en cultivo sin suelo: exigências en aportación y manejo. Resultados experimentales en cultivo de pepino en perlita. In: MILAGROS, M. F.; GÓMEZ, I. M. C. (Ed.). Cultivos sin suelo II. 2. ed. Almería: DGIFA-FIAPA - Caja Rural de Almería, 1999. p. 287-305.

DUARTE, T. S.; PEIL, R. M. N.; MONTEZANO, E. M. Crescimento de frutos do meloeiro sob diferentes relações fonte:dreno. Horticultura Brasileira, Brasília, v. 26, n. 3, p. 342-347, 2008.

DUARTE, T. S.; PEIL, R. M. N.; BACCHIS, S.; STRASSBURGER, A. S. Efeito da carga de frutos e concentrações salinas no crescimento do meloeiro cultivado em substrato. Horticultura Brasileira, Brasília, v. 26 , n. 3, p. 348-353, 2008

ESPÍNOLA, H. N. R.; ANDRIOLO, J. L.; BARTZ, H. R. Acúmulo e repartição da massa seca da planta de pepino tipo conserva sob três doses de nutrientes minerais. Ciência Rural, Santa Maria, v. 31, n. 3, p. 387-392, 2001.

FILGUEIRAS, R. C.; TAKAHASHI, H. W.; BENINNI, E. R. Y. Produção de alface hidropônico em diferentes condutividades elétricas. Semina: Ciências Agrárias, Londrina, v. 23, n. 2, p. 157-164, 2002.

FREIRE, A. L. de O.; SARAIVA, V. P.; MIRANDA, J. R. P. de; BRUNO, G. B. Crescimento, acúmulo de íons e produção de tomateiro irrigado com água salina. Semina: Ciências Agrárias, Londrina, v. 31, p. 1133-1144, 2010. Suplemento 1.

HEUVELINK, E. Effect of fruit load on dry matter partitioning in tomato. Scientia Horticulturae, Amsterdam, v. 69, n. 1, p. 51-59, 1997.

KITTAS, C.; KATSOUlAS, N.; BAILlE, A. Transpiration and energy balance of a greenhouse rose crop in Mediterranean summer conditions. Acta Horticulturae, Cartagena, v. 559, p. 395-400, 2001.

KLOSOWSKI, E. S.; LUNARDI, D. M. C.; SANDANIELO, A. Determinação do consumo de água e do coeficiente de cultura da abóbora na região de Botucatu, SP. Revista Brasileira de Engenharia Agrícola e Ambiental, Campina Grande, v. 3, n. 3, p. 409-412, 1999.

LI, Y. L. Analysis of greenhouse tomato production in relation to salinity and shoot environment. 2000. Tese (Doutorado em Horticultura) - Wageningen Agricultural University, Wageningen.

MARCELIS, L. F. M. Simulation of biomass allocation in greenhouse crops: a review. Acta Horticulturae, Saumane, n. 328, p. 49-67, 1993.

Sink strength as a determinant of dry matter partitioning in the whole plant. Journal of Experimental Botany, v. 47, p. 1281-1291, 1996. Special Issue.

MONTEITH, J. L. Solar radiation and productivity in tropical ecosystems. Journal of Applied Ecology, v. 9, n. 3, p. 747-766, 1972.

MONTEZANO, E. M. Eficiência no uso da água e dos nutrientes e relações de contaminação de cultivos de alface em sistema hidropônico. 2003. Dissertação (Mestrado em Agronomia) - Faculdade de Agronomia Eliseu Maciel. Universidade Federal de Pelotas, Pelotas.

Sistemas de cultivo sem solo para a cultura do meloeiro. 2007. Tese (Doutorado em Agronomia) Faculdade de Agronomia Eliseu Maciel. Universidade Federal de Pelotas, Pelotas.

PEIL, R. M. N.; GALVÉZ, J. L. Effect of fruit removal on growth and biomass partitioning in cucumber. Tsukuba, Acta Horticulturae, Saumane, v. 588, p. 69-74, 2002.

Reparto de materia seca como factor determinante de la producción de las hortalizas de fruto cultivadas em invernadero. Revista Brasileira Agrociência, Pelotas, v. 11, n. 1, p. 05-11, 2005.

STANGHELLINI, C. Transpiration of greenhouse crops. An aid to climate management. 1987. Tese (Doutorado) Wageningen Agricultural University, Wageningen. 